\title{
TEORIA CRÍTICA E PESQUISA SOCIAL: DA DIALÉTICA À RECONSTRUÇ̄̃̃*
}

\author{
OLIVIER VOIROL \\ TRADUÇÃO DE BRUNO SiMÕES
}

\section{RESUMO}

Os desenvolvimentos teóricos recentes da Teoria Crítica têm pas 810 a largo da preocupação com a pesquisa social - seja pela pouca importância dada ao "teste" empírico das Teteias teóricas, seja pela ausência de estímulo a novos projetos de pesquisa empírica no campo da Teoria Crítica. Essa tendência implica uma importante "mudança" teórica em relação ao antigo programa dialético da Teoria Crítica proposte por Max Horkheimer na década de 1930. O artigo ressalta algumas dificuldades atinentes à articulação produtiva ehrteteoria e pesquisa - com prejuízo, creio, para ambas, filosofia e ciências sociais.

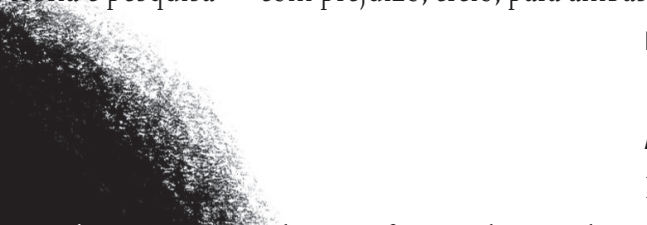

PALAVRAS-CHAVE: Teoria Crítica; pesquisa social; dialética; reconstrução.

\section{ABSTRACT}

Recent theoretical developments in Critical Theory seem to happen without great cessideration for social research — neither for empirical "tests" of theoretical ideas, nor for launching new empirical reseazch projects in the field of Critical Theory. This evolution suggests an important theoretical "shift" in comparison with the early horkheimerian dialectical program of Critical Theory. This tendency raises some difficulties linked to the proftuctive articulation of theory and research - at the lost of both of them, philosophy and social sciences.

[*] Gostaria de expressar meit agradecimentos a Adrian Gurza fy valle pelos preciosos comentiutes sobre meu artigo apresentado $n$ e $\mathrm{Co}$ lóquio de Teoria Crítica de Sât Paulo (Cebrap, 3-5 de outubro de 2011 ).
KEYWORDS: Critical theory; social research; dialectics; reconstruction.
A última década viu surgir inúmeros debates sobre a atualidade da Teoria Crítica e o papel atual dessa tradição teórica.Uma das questões mais importantes refere-se às fundações normativas da crítica - mas também ao lugar que a ética comunicativa, ou o conceito de reconhecimento, deve ocupar nessa atualização. Para outros autores, menos preocupados com questões normativas e mais interessados na "primeira geração" da Teoria Crítica, o papel do pensamento não identitário de Adorno também ganhou grande relevância. Nesses debates valiosos, no entanto, uma questão tem sido de certa forma negligenciada: o lugar da pesquisa social no desenvolvimento efetivo da Teoria Crítica. Comparada à importância dada à pesquisa social no primeiro projeto da Teoria Crítica, formulado por Max Horkheimer na década de 1930, e à centralidade da pesquisa social 
em todo o desenvolvimento desse grupo de pensadores, a situação é bastante surpreendente. Com efeito, para muitos dos tributários da Teoria Crítica contemporânea, é como se a questão da pesquisa social não fosse prioritária em face da primazia conferida às questões normativas. $O$ fato de a Teoria Crítica progredir hoje principalmente no campo da filosofia social e política - e não no da economia, da sociologia ou da psicanálise, como no passado - éum importante sinal e desempenha um papel considerável nessa tendência. Para a maioria dos pensadores críticos contemporâneos, como Axel Honneth, que ainda a considera uma tarefa importante para a Teoria Crítica, o lugar dado à pesquisa social em suas elaborações filosóficas não é tão central quanto para seus predecessores no Instituto de Pesquisa Social.Ainda que seja um defensor da ideia de uma cooperação necessária entre pesquisa social e filosofia social, Axel Honneth também salienta as dificuldades reais desse projeto'. De maneira geral, parece que os desenvolvimentos teóricos recentes dessa tradição intelectual acontecem sem grande consideração pela pesquisa social — nem pelos "testes" empíricos das ideias teóricas, tampouco pelo estímulo a novos projetos de pesquisa empírica no campo da Teoria Crítica. Essa evolução implica uma importante "mudança" teórica em relação ao antigo programa dialético da Teoria Crítica proposto por Horkheimer. Pretendo, neste artigo, ressaltar algumas dificuldades atinentes à articulação produtiva entre teoria e pesquisa - com prejuízo, creio, para ambas, filosofia e ciências sociais.

As dificuldades atuais para reunir filosofia social e pesquisa social têm muitas razões - que são complexas e não podem ser tratadas aqui em detalhes - , para além de questões teóricas "puras". Essas razões residem, por exemplo, na forma específica como estão organizadas as universidades, no quadro restritivo da pesquisa científica, que dificilmente admite a cooperação entre filósofos e pesquisadores empíricos, etc. Sem deixar de lado esses fatores explicativos importantes, neste artigo pretendo me concentrar nas questões teóricas concernentes à relação entre pesquisa social e Teoria Crítica. (1) Mais precisamente, pretendo primeiramente retomar o modelo dialético e materialista de pesquisa social e teoria crítica desenvolvido por Max Horkheimer no início da década de 1930, que molda o fundamento de toda a Teoria Crítica. Mostrarei como Horkheimer veio a conceber a relação dialética entre ciência e filosofia, almejando com isso ultrapassar, de maneira crítica, suas respectivas "crises". (2) Em segundo lugar, pretendo ressaltar a "virada reconstrutiva" apresentada por Jürgen Habermas quarenta anos depois como consequência da discussão crítica que se seguiu ao seu importante livro Conhecimento e interesse (1968). Após ter enfatizado os principais aspectos da reconstrução, tentarei mostrar como esta diz respeito às ciências empíricas e que tipo de relação ela
[1] Ver Honneth, Axel. "Vom schwierigen Geschäft der Traditionsbewahrung. Zur Zukunft des Instituts für Sozialforschung". In: Boll, M. e Gross, R. H. (orgs.). Die Frankfurter Schule und Frankfurt. Eine Rückkehr nach Deutschland. Göttingen: Wallstein, 2009, pp. 288-97. 
acarreta entre teoria e pesquisa científica. (3) Como conclusão, gostaria de pôr em questão tanto as consequências quanto os problemas da reconstrução na relação entre Teoria Crítica e pesquisa social.

\section{DIALÉTICA}

[2] Horkheimer, Max. Critical theory: selected essays. Nova York: Continuum, 1972. A concepção inicial que Horkheimer teve da Teoria Crítica foi amplamente discutida por muitos autores. Para uma apresentação sistemática, ver, por exemplo: Dubiel, Helmut. Wissenschaftsorganisation und politische Erfahrung: Studien zur frühen Kritischen Theorie. Frankfurt: Suhrkamp, 1978; Held, David, "Horkheimer's formulation of critical theory". In: Introduction to Critical Theory. From Horkheimer to Habermas. Berkeley/Los Angeles: University of California Press, 1980, pp.174-99; Brandt, Gerhard. "Max Horkheimer und das Projekt einer materialistischen Gesellschaftstheorie". In: Schmidt, A. (ed.).Max Horkheimer heute: Werk und Wirkung. Frankfurt: Fischer, 1986; Asbach, Olaf. Kritische Gesellschaftstheorie und historische Praxis. Entwicklungen der Kritischen Theorie bei Max Horkheimer 1930-1943. Frankfurt: Peter Lang, 1997; mais recentemente: Abromeit, John. Max Horkheimer and the foundations of the Frankfurt School. Cambridge University Press, 2011. Para uma apresentação crítica, ver Honneth, Axel. "Horkheimers ursprüngliche Idee. Das soziologische Defizit der Kritischen Theorie". In: Kritik derMacht. Reflexionsstufen einer kritischen Gesellschaftstheorie. Frankfurt: Suhrkamp, 1986, pp. 12-42.

[3] Horkheimer, Max, especialmente "Notes on science and the crisis", in: Horkheimer, op. cit., pp.3-10.

[4] Essas ideias sobre a oposição sujeito/objeto, primeiramente formuladas no início da década de 1930 , são posteriormente desenvolvidas na Dialética do esclarecimento. Adorno ofereceu uma formulação final no seu (último) texto sobre epistemologia, "Subject and object" (1969), in: Arato, Andrew e Gebhardt, Eike (eds.). The essential Frankfurt School reader. Nova York: Continuum, 1978, pp. 497-511.
No início da década de 1930, Max Horkheimer publicou vários textos - que integram hoje em dia o núcleo conceitual da Teoria Crítica - sobre a história da ciência, bem como sobre a história da filosofia burguesa - ambas teriam ingressado numa profunda crise ${ }^{2}$. De acordo com Horkheimer, o projeto científico do início da era burguesa possibilitou um novo tipo de conhecimento sobre o mundo exterior? Dirigido contra as estruturas tradicionais do pensamento característico de uma sociedade tradicional e feudal, esse projeto produziu um conhecimento racional sobre o mundo "objetivo" destituído de referências a elementos religiosos ou mágicos. A ciência trouxe um tipo de relação entre os sujeitos cognoscentes e o mundo baseada na observação sistemática e na descrição racional. O pensamento científico significa, aqui, uma ruptura com visões tradicionais do mundo porque este é concebido não como uma esfera moldada por forças mágicas, mas como produto de um processo que pode ser compreendido, explicado e reproduzido por sujeitos humanos. O sujeito cognoscente torna-se consciente de si mesmo como um ser independente diante de um mundo "objetivo", que pode ser racionalmente compreendido graças a métodos sistemáticos de observação4. Desse modo, possibilitou-se um crescente conhecimento sobre a natureza e o mundo objetivo, bem como sobre novas possibilidades de controle e dominação da natureza. Essa contínua dissolução da relação mágica que presidia o mundo encontrou suas mais diferentes expressões durante o Iluminismo no século XVIII atrelada à sua noção de razão.

$\mathrm{Na}$ medida em que as práticas científicas permitem o estabelecimento de uma relação "simétrica" com o mundo exterior, elas contribuem para a emancipação. Mas, como um meio de dominação do mundo exterior, a ciência tornou-se uma força de produção que facilmente se integra aos interesses das relações capitalistas de produção. Horkheimer insiste no fato de que a ciência nunca está livre de interesses sociais e que o seu desenvolvimento deve ser sempre entendido em contextos históricos e sociais específicos. A ciência é fundamentalmente social e condicionada por mudanças sociais. Ao mesmo tempo, a ciência é capaz de produzir um conhecimento que não pode ser reduzido a contextos históricos e relações sociais porque tal conhecimento está relacionado com uma verdade universal — um critério que não pode ser governado por interesses sociais por causa da sua relação com processos de pesquisa independentes. As condições 
sociais e os contextos históricos permitem (ou não) a possibilidade de relacionar o projeto científico, a racionalidade crescente e o controle por esta alcançado aos sujeitos humanos. No curso da história, alguns momentos e situações são mais propícios do que outros para o verdadeiro desenvolvimento do núcleo do projeto científico. De acordo com Horkheimer, as práticas científicas têm que se desenvolver sob pressão dos interesses sociais na sociedade capitalista, de modo que a ciência se desenvolve de uma maneira específica e problemática. A lacuna entre o sujeito cognoscentee a realidade objetiva surge no curso do desenvolvimento da ciência, o que possibilita considerar o mundo objetivo de uma maneira reificada, independentemente dos sujeitos cognoscentes - o positivismo. Com a ampliação dessa lacuna, o mundo objetivo transforma-se cada vez mais num "objeto" reificado submetido às forças produtivas das ciências, estendendo o poder do controle humano e exercendo uma dominação, bem como uma exploração sistemática, sobre a natureza exterior.

A ciência é influenciada pelo capitalismo; e as tendências que impedem o progresso científico são cada vez mais importantes nas atuais contradições do capitalismo. O uso sistemático da ciência tornou-se desproporcional em relação às necessidades humanas: a sociedade exige um autoconhecimento qualitativo, mas a ciência oferece apenas uma acumulação quantitativa de especializações particulares. A ciência está submetida a uma "especialização caótica", em que cada domínio mantém-se sob a ilusão de um monopólio da verdade. A proliferação de disciplinas científicas especializadas, explorando em detalhes seu universo social separado, sem que haja uma comunicação entre elas, impossibilita a concepção da sociedade como um todo. Essa proliferação da especialização instrumental parcial a serviço de interesses econômicos não contribui para o desenvolvimento do conhecimento racional. Isso leva à impossibilidade de se compreender a sociedade como um todo e oferece uma representação irracional da realidade. $\mathrm{O}$ estado de crise na ciência burguesa acentua a crise na sociedade através da sua própria organização. E esse estreitamento da racionalidade científica leva a uma atitude positivista em que a ciência não é capaz de ser autorreflexiva.

Isso gera um conflito entre a ciência empírica e a filosofia especulativa: o mundo é visto como "objetivo" e neutro sem estar conectado a um sujeito cognoscente. Horkheimer critica a atitude positivista, que consiste em acreditar na neutralidade de uma prática científica que não se baseia no questionamento filosófico. Além disso, as práticas científicas não são mais orientadas pelo princípio interno de investigação da verdade universal, mas pelas demandas sociais e interesses econômicos, o que resulta numa crise profunda na sua relação com a verdade. Isso contribui para uma crise do projeto científico moderno 
[5] Horkheimer, Max. "The present situation of social philosophy and the task of an Institute for Social Research". In: Between philosophy and social sciences: selected early writings. Cambridge:The MIT Press, 1995, p.1.

[6] Ibidem, p. 8 .

[7] Ibidem.

[8] Ibidem. e da razão, impossibilitando a autorreflexão racional da sociedade. Como consequência, sob o regime capitalista, a ciência contribui para uma cegueira ideológica, reforçando a atitude passiva e contemplativa dos sujeitos sociais num mundo destituído de qualquer sentido. O fracasso do projeto científico sob a vigência do regime capitalista contribui para manter as verdadeiras injustiças sociais e bloqueia as progressivas transformações sociais.

A filosofia enfrenta uma crise semelhante porque está presa numa metafísica especulativa sem qualquer cooperação com as ciências empíricas. Horkheimer retoma uma antiga tradição filosófica (Kant e Hegel são as principais figuras dessa tradição) que está voltada, sobretudo, para a análise de "toda cultura material e intelectual da humanidade" (Estado, lei, economia, religião) relacionada ao contexto da "vida social humana" e que busca interpretar filosoficamente "as vicissitudes do destino humano - o destino dos humanos não como indivíduos atomizados, mas como membros de uma comunidade" 5 .Além do mais, Horkheimer ressalta que essa tradição filosófica - a filosofia social - voltada para a "vida social dos humanos" experimenta, no momento atual, grandes dificuldades e encontra-se em crise. Ela precisa lidar com a "existência e a validade simultâneas de vários conceitos de realidade" específicos a "diferentes áreas do conhecimento e esferas da vida" "; no entanto, nenhuma prioridade entre esses conceitos está objetivamente fundada. De acordo com Horkheimer, tal dificuldade pode ser "solucionada" apenas na medida em que for utilizada a "investigação concreta de um objeto"7. Ademais, essa tradição filosófica está presa numa antiga divisão de trabalho entre a conceitualização teórica e as ciências empíricas, em particular as ciências sociais.Assim, essa tradição considera erroneamente que a "sociologia nada tem a dizer sobre o grau de realidade ou sobre o valor desses fenômenos" e, por outro lado, que as questões fundamentais da filosofia social podem trazer à baila "posições cruciais, embora nenhuma verdade generalizadamente válida que possa ser combinada com investigações amplas e variadas" 8 . Depois de Horkheimer, o pensamento filosófico clássico sobre a realização histórica da razão não pode ser levado adiante na sua forma clássica, deixando de considerar as descobertas empíricas baseadas na pesquisa científica empírica. Esse ceticismo não diz respeito apenas à filosofia especulativa burguesa, mas também à filosofia da história hegeliano-marxista, cuja ligação entre progresso, história e razão é tida como certa em todos os círculos marxistas: o progresso da razão é incorporado numa práxis efetiva (de produção) endossada por um sujeito social, o proletário, que deve realizar os potenciais emancipatórios da razão incorporada na história. Entretanto, diante da dramática ascensão do nazismo na Alemanha do fim da década de 1920 , esse modelo histórico pareceu, no mínimo, pouco significativo para 
explicar a situação daquele momento, e precisou sem dúvida de uma profunda atualização. A filosofia atingiu seus próprios limites numa situação dramática, em que outros tipos de conhecimento foram necessários para estabelecer um diagnóstico adequado do período: a pesquisa social foi um modo importante para encontrar esse "ajuste".

Horkheimer tenta dar uma resposta para a crise que se reflete tanto na ciência quanto na filosofia, formulando um programa alternativo e salvando ambas segundo a forma de uma abordagem dialética e materialista. De um lado, ele tenta salvar o projeto científico sem abrir mão da pesquisa empírica, a despeito de sua forte crítica do positivismo. De outro, ele salva a filosofia ao defender a posição particular desta em relação à ciência9 - sobretudo porque a filosofia admite a perspectiva da totalidade. Entretanto, apenas o "trabalho que se opera sobre o objeto", baseado em métodos científicos, nos protege de uma concepção filosófica desvinculada do mundo. Em outras palavras, a filosofia pode responder à crise da ciência da mesma forma que a ciência pode responder à crise da filosofia. O programa de pesquisa dialética consegue escapar tanto dos limites da filosofia especulativa quanto das ciências empíricas especializadas, buscando preencher a lacuna entre uma construção abstrata e especulativa desprovida de exploração empírica e uma descrição empírica factual, autossuficiente e detalhada desprovida de qualquer quadro teórico de síntese ${ }^{10}$. Horkheimer enfatiza a ideia de uma "penetração e desenvolvimento contínuo e dialético da teoria filosófica e da práxis científica especializada" ${ }^{11}$.

De acordo com Horkheimer, a crise da ciência sob o regime capitalista pode ser superada graças à concepção materialista de ciência, cujos principais elementos já haviam moldado as origens do projeto científico. Nas primeiras etapas da ciência, os métodos sistemáticos de observação desenvolvidos por Copérnico, Galileu e Newton referem-se a uma concepção materialista do mundo que o considera como um conjunto de processos mecânicos separados da teologia, o que pela primeira vez permitiu uma concepção racional do mundo exterior. Nesse estágio inicial de observação do mundo, considerado como "objeto", a racionalidade científica ainda não havia atingido o estágio avançado em que os interesses sociais e processos capitalistas controlam a investigação científica. O objeto exterior ainda é conhecido de uma maneira não instrumental que, fundamentalmente, delineia a possibilidade de uma "alteridade" e de uma relação "simétrica" entre sujeito cognoscente e objeto de conhecimento. Esse conhecimento materialista não considera o mundo como um "objeto" independente que leva a uma possível "objetividade": um conhecimento independente de um espectador passivo e neutro. Esse materialismo científico em estágio inicial supôs uma dialética entre um sujeito cognoscente e um objeto de conhecimento. Ele assume que o sujeito de conheci-

\begin{abstract}
[9] Especialmente sobre esse ponto, ver seu texto (posterior), "The social function of philosophy" (1939), in: Horkheimer, Critical theory: selected essays, op. cit.
\end{abstract}

[10] Habermas insiste na dimensão "pós-metafísica" desse projeto: ver Habermas, Jürgen. "Remarks on the development of Horkheirmer's work". In: Benhabib, S., Bonß, W. e McCole, J. (eds.). On Max Horkheimer. New perspectives. Cambridge: The мIT Press, 1993, pp. 49-66.

[11] Horkheimer, "The present situation...",op.cit.,p. 9.Aquestão sobre a relação entre filosofia e ciências sociais no programa inicial de Horkheimer foi discutida por muitos autores. Ver, por exemplo: Söllner, Alfons. Geschichte und Herrschaft. Eine kritische Studie zum Verhältnis von Philosophie und Sozialwissenschaft in der Kritischen Theorie 1929-1942. Frankfurt: Suhrkamp, 1979; McCarthy, Thomas. "The idea of a Critical Theory and its relation to philosophy". In: Benhabib, Bonß e McCole (eds.), On Max Horkheimer..., op. cit., pp. 127-52; Brunkhorst, Hauke. "Dialectical positivism of happiness: Horkheimer's materialist deconstruction of philosophy". In: Benhabib, Bonß e McCole (eds.), On Max Horkheimer..., op. cit., pp. 67-98. 
[12] O tema do materialismo interdisciplinar é central, mas não tenho como desenvolvê-lo aqui. Sobre esse ponto, ver: Jay, Martin. "Max Horkheimer and the retreat from hegelian marxism". In:Marxism and totality. University of California Press, 1984, pp. 196-219; Bonß, Wolfgang. "The Program of Interdisciplinary Research and the beginnings of Critical Theory". In: Benhabib, Bonß e McCole (eds.), OnMax Horkheimer..., op. cit., pp. 99-126; Bonß, Wolfgang e Schindler, Norbert. "Kritische Theorie als interdisziplinärer Materialismus". In: Honnet, A.e Bonß,W.Sozialforschung als Kritik. Frankfurt/M.: Suhrkamp, 1982, pp. 31-66; Voirol, Olivier. «Matérialisme interdisciplinaire et critique de la culture». In: Noppen, Pierre-François, Macdonald, Iain e Raulet, Gérard (dirs.). Les normes et le possible: héritage et perspectives de l'École de Francfort. Paris: Éditions de la MSH, 2012. mento sabe claramente quais são os objetivos de sua atividade de pesquisa, o que implica uma autorreflexão sobre a prática científica e os interesses que a orientam. Como Horkheimer demonstra em "Teoria Tradicional e Teoria Crítica" (1937), nessa atividade está presente uma reflexão sobre os interesses sociais que governam a abordagem científica - cf. os "interesses das massas para a supressão da injustiça". Em outras palavras, essa abordagem materialista e dialética difere do positivismo porque ela não concebe seu "objeto de pesquisa" como algo separado do sujeito cognoscente, como independente e neutro; $e$ tampouco considera o sujeito cognoscente como neutro e "passivo": o sujeito tem que tornar explícitos seus próprios interesses de conhecimento. Em particular, essa filosofia deve tornar claro o quadro de investigação científica, de modo que os pesquisadores desenvolvam uma autocompreensão normativa de seu trabalho. Um aspecto essencial dessa autorreflexão consiste em evitar que o objeto de investigação esteja isolado de seus contextos sociais e históricos, das práticas e processos sociais em que ele emergiu e da totalidade social da qual necessariamente faz parte - essa é a razão pela qual conceitos como totalidade e mediação são centrais no projeto de pesquisa interdisciplinar conduzido pelo Instituto ${ }^{12}$.

A partir desse esclarecimento necessário tanto sobre o sujeito cognoscente quanto sobre o objeto do conhecimento - queé a condição para uma teoria crítica superaro positivismo empírico-, Horkheimer desenvolveu uma estrutura que liga dialeticamente pesquisa e teoria. O propósito da pesquisa científica é construir uma "pesquisa concreta" numa constante exploração, confrontando o quadro teórico com as práticas reais - o que é impossível com base apenas na filosofia. Nessa investigação, a adequação da construção teórica é posta à prova através de exames empíricos que lidam com configurações concretas do objeto: dessa forma, a pesquisa obriga a construção teórica a ser constantemente redefinida.Ao mesmo tempo, a pesquisa é guiada por preconcepções teóricas que são esclarecidas à luz de seus interesses de conhecimento e objetivos emancipatórios. Nesse sentido, Horkheimer concebeu um entrelaçamento da teoria filosófica com a prática científica especializada: em primeiro lugar, a teoria deve manter informadas as investigações empíricas em seu programa de pesquisa equadro de questionamento; a ligação com a pesquisa social oferece uma base crítica para sua construção em função da mudança de processos empíricos. Em segundo, a teoria é constantemente questionada pelo processo investigativo, de modo a oferecer, progressivamente, uma síntese teórica que esteja em contato com as evoluções sociais contemporâneas eficientes. Por fim, a teoria proporciona uma estrutura reflexiva para a abordagem empírica sem permitir a segmentação do fenômeno social, como o fazem as ciências empíricas ultraespecializa- 
das, permitindo-nos considerar fenômenos singulares à luz da sociedade como um todo. De acordo com Horkheimer, a Teoria Crítica deve substituir a filosofia especulativa tradicional pelo "trabalho objetivo" de investigação conduzido pelas ciências empíricas. O materialismo dialético de Horkheimer pretende ir além do sentido tradicional da metafísica, substituindo o ponto de vista especulativo desta pela prática científica investigativa autorreflexiva - sem, no entanto, se dissolver em propósitos científicos.

Essa relação entre reflexão teórica e pesquisa empírica é claramente influenciada pelo método dialético de pesquisa (Forschung) e apresentação (Darstellung) desenvolvido por Marx no Capital. Enquanto a pesquisa explora um objeto real a fim de analisar suas várias formas e desenvolvimentos, a apresentação desenvolve abstrações conceituais empiricamente enraizadas de modo a desenvolver progressivamente uma apresentação mais completa desse objeto. Essa apresentação põe em questão algumas etapas passadas de apresentação - por exemplo, a economia política burguesa com vistas a oferecer uma maior compreensão do objeto ${ }^{13}$. Em vez de emergir de dados empíricos completamente "desguarnecidos", a pesquisa sempre se inicia com uma apresentação passada, de modo a ensejar um processo exploratório que almeja uma apresentação coerente do objeto. O papel principal dado por Marx à apresentação, como ponto de partida da pesquisa e como "poder" que se atribui à investigação para reconfigurar apresentações anteriores, influenciou a crítica de Horkheimer ao empirismo positivista, na sua defesa de uma filosofia articulada com a pesquisa social. A pesquisa social promovida no Instituto de Pesquisa Social devia se desenvolver por meio das técnicas mais atuais de investigação social, ao passo que a apresentação completa desse trabalho, no quadro de uma nova síntese teórica, devia ser a tarefa da filosofia social. Desse modo, as apresentações teóricas são alimentadas pelas pesquisas empíricas de maneira a produzir uma síntese conceitual atualizada que, simultaneamente, define o quadro de futuras pesquisas. Entretanto, não se deve compreender essa ideia no sentido positivista de uma verificação - ou falsificação - de uma hipótese teórica, pois o que está em jogo é a ideia de uma ampliação da síntese teórica capaz de torná-la coerente com o seu objeto.

Para Horkheimer, a dialética materialista deve permanecer "aberta", e o núcleo do método dialético deve residir no reconhecimento dos limites de qualquer projeto teórico. Em oposição a qualquer construção teórica abstrata, cujos objetivos pretendem produzir um conhecimento "acabado" sobre o mundo real que se buscou conceitualizar, a dialética admite seu caráter incompleto e inacabado. Pois esta considera que a realidade adquire forma sob os contínuos mo-
[13] Ver Ollman, Bertell. Dance of the dialectic. Steps in Marx's method. Urbana/Chicago: University of Illinois Press, 2003, pp. 127-54. 
[14] Há muitas interpretações conflitantes da história da Teoria Crítica relacionadas a esse ponto: Helmut Dubiel afirma que esse modelo já tinha sido abandonado em 1937 (Dubiel, op. cit.); Axel Honneth considera que a íntima relação entre filosofia e pesquisa social desapareceu após a virada ocasionada pela Dialética do esclarecimento (ver Honneth, Axel. Critique of power. Cambridge: The MIT Press, 1988); Alex Demirović enfatiza a ideia de que essa dialética ainda estava presente na pesquisa empírica do Instituto, quando de seu retorno para a Alemanha e até a morte de Adorno em 1969 (Demirović, Alex. Der nonkonformistische Intellektuelle. Frankfurt: Suhrkamp, 1999). vimentos da práxis, a qual não pode ser inteiramente apreendida por nenhum conceito teórico. Uma vez que a situação está em contínua mudança, a teoria pode "apenas" ser parte de uma conceitualização exploradora que nunca écapaz de ser completamente bem-sucedida - em outras palavras, as práticas estão sempre um passo adiante de qualquer esforço de teorização. Uma "dialética aberta" admite, pois, as persistentes tensões entre teoria e realidade; ela saúda, por assim dizer, um tipo de "humildade do conhecimento" e a necessidade de constantemente redefinir-se ao travar contato com o objeto. Diferentemente do idealismo hegeliano, a dialética renuncia qualquer tipo de identidade estabelecida entre conceito e objeto, enfatizando a irreduzível tensão entre eles. Por um lado, o sujeito cognoscente concebe a realidade como um "não ser", dando abertura para possibilidades (utópicas) que a própria realidade não contém. Por outro, o objeto investigado resiste a tal pensamento na medida em que ele obriga a teoria a reajustar-se à realidade prática. Por fim, uma "dialética aberta" é um processo interminável de desenvolvimento do conhecimento, num ciclo permanente de redefinição, constantemente buscando conceitualizar a mudança das práticas na realidade, sem qualquer possibilidade de se encerrar tal processo.

Adialética da pesquisa e teoria continuou sendo o principal modelo para reunir filosofia e ciências empíricas na Teoria Crítica até o fim da década de $1960^{14}$, incluindo o tempo em que o Instituto (durante exílio) mudou o seu principal foco teórico. Mas seesse modelo definiu a concepção filosófica geral de pesquisa social, ele também assumiu diferentes formas ligadas a diferentes períodos ao longo do desenvolvimento da Teoria Crítica - não apenas por causa do seu desenvolvimento teórico, mas também pelas condições dramáticas sob as quais o Instituto teve que sobreviver. Eu não seria capaz de desenvolver esse ponto aqui; seria necessária outra intervenção voltada apenas para o esclarecimento dessa ideia. Permitam-me apenas ressaltar a ideia segundo a qual a dialética da pesquisa e teoria formulada pelo jovem Horkheimer teve a mais importante influência sobre a Teoria Crítica. Eu gostaria agora de considerar outro modelo que, em minha opinião, pôs de volta o modelo dialético na Teoria Crítica.

\section{RECONSTRUÇÃo}

A publicação de Conhecimento e interesse (1968), de Jürgen Habermas, constitui uma etapa crucial no desenvolvimento da Teoria Crítica e resulta em uma nova relação entre filosofia e pesquisa científica. Nessa obra, buscou-se conceber uma alternativa epistemológica ao positivismo e à ascensão das ciências técnicas, baseando-se na diferenciação de três interesses constitutivos do conhecimen- 
to: um interesse empírico-analítico no controle potencial, um interesse hermenêutico-histórico na compreensão e um interesse crítico-emancipatório na liberdade e autonomia. Habermas insistiu nos interesses emancipatórios específicos das ciências críticas, cujos objetivos são produzir uma autorreflexão racional dos sujeitos sociais, graças a um tipo de abertura que foi tornada possível através de métodos científicos baseados na superação de obstáculos para uma "verdadeira" comunicação.

De fato, a mudança teórica mais importante é introduzida por Habermas como consequência dos debates e críticas que se seguiram à publicação de seu livro. Cinco anos depois (1973), no posfácio da nova edição, ele comenta várias objeções dirigidas ao livro, reconhecendo que ele tinha feito sua pesquisa por meio da "reconstrução das condições do conhecimento" sem apresentar uma diferenciação adequada entre autorreflexão e reconstrução. Ele reconhece ter compreendido, apenas após o livro, que o uso tradicional da reflexão, emergindo com o idealismo alemão, sobrepôs (e misturou) duas concepções do termo: de um lado, a reflexão sobre as condições de possibilidade de um sujeito que conhece, age e fala em geral; e, de outro, a reflexão sobre os limites inconscientes que restringem um sujeito (coletivo ou individual) no seu processo de formação. Embora o primeiro tipo de reflexão assuma a forma (a partir de Kant e seus sucessores) de uma fundação transcendental do conhecimento possível (e da ação moral), o segundo tipo também adquiriu o sentido de "reconstrução racional das regras ou sistemas cognitivos"15. Desse modo, Habermas apresentou uma diferenciação entre uma reflexão transcendental, que busca refletir sobre as condições subjetivas necessárias com base em um conhecimento, e uma reflexão não transcendental, cujo objetivo é reconstruir o sistema genérico de regras que estão na base das competências comuns. Assim, a ideia de regras genéricas em Chomsky concerne mais às competências verdadeiras de sujeitos empíricos não individuais do que às condições transcendentais. A reconstrução difere da reflexão porque se refere a um sujeito empírico anônimo atuante e não a um sujeito abstrato transcendental ${ }^{16}$.

Feita a diferenciação entre reflexão e reconstrução, Habermas diferencia as ciências "críticas" das ciências "reconstrutivas". As ciências críticas (e.g. psicanálise) dizem respeito à reflexão porque buscam atingir o caráter reflexivo de um sujeito que não se compreende bem por causa das ilusões, bem como dos modelos restritivos de percepção e ação que precisam ser descobertos para libertá-lo deles. Em outras palavras, as ciências críticas contestam a ideia de um conhecimento considerado deformado ou falso tendo em vista um "verdadeiro" conhecimento. Em contrapartida, as "ciências reconstrutivas" (como
[15] Cf.Conhecimento e interesse, posfácio, 1973 .

[16] Para algumas prolongadas discussões sobre o modelo de reconstrução de Habermas, ver: McCarthy, Thomas. Ideals and illusions. Deconstruction and reconstruction in Critical Theory. Cambridge: The MIT Press, 1993; Outhwaite, William. "Rekonstruktion und methodologischer Dualismus". In: Müller-Doohm, Stefan (ed.). Das Interesse der Vernunft. Rückblicke auf das Werk von Jürgen Habermas seit "Erkenntnis und Interesse". Frankfurt: Suhrkamp, 200o, pp. 218-41; Garz, Detlef. "Kritik, Hermeneutik, Rekonstruktion. Über den Stellenwert der Methode bei Jürgen Habermas". In: Müller-Doohm, Stefan (ed.).op.cit.,pp. 201-17; Pedersen, Jørgen. "Habermas' method: rational reconstruction". Philosophy of the Social Sciences, 38, 4, 2008, pp.457-85. 
lógica, linguística, moral e psicologia cognitiva) exploram sistemas usuais de regras que, como tais, não são postas em questão nas atividades práticas porque formam implicitamente regras e normas fundamentais de nossas atividades práticas. Os sistemas linguísticos de regras são, nesse sentido, precondições implícitas necessárias que possibilitam as discussões racionais. As ciências genéticas referem-se à reconstrução na medida em que buscam explicar processos de aprendizado das competências cognitivas, linguísticas e morais com base em modelos lógicos implícitos.

Para resumir as características mais importantes das "ciências reconstrutivas" em comparação com as "ciências críticas", Habermas delineia três aspectos que as diferem entre si. Primeiramente, as bases da reconstrução são práticas implícitas ou esquemas cognitivos, e não experiências inconscientes reveladas na pseudo-objetividade de um método reflexivo. Em segundo lugar, a reconstrução considera os sistemas anônimos de regras como uma base geral de referência para todos os sujeitos, e não como sujeito individual e particular em seu processo de formação da identidade. Terceiro, a reconstrução explicita os sistemas intuitivos de conhecimento e de competências sem que isso tenha consequências práticas, ao passo que a reflexão busca tornar conscientes as estruturas inconscientes a fim de escapar da falsa consciência. Habermas segue adiante na sua defesa da reconstrução, considerando que a reflexão por meio das ciências críticas depende de reconstruções anteriores, e que as ciências críticas dependem fundamentalmente da reconstrução. Ele observa que é impossível descrever uma deformação da comunicação sem se referir a condições universais de uma comunicação bem-sucedida - as condições de possibilidade de um discurso "normal". Assim, depois de Habermas, um método crítico como a psicanálise deve necessariamente ter uma "pré-noção" do entendimento comunicativo não deformado (de um sujeito consigo próprio) de modo a poder compreender as deformações patológicas.

A reconstrução surge como um método que busca revelar estruturas profundas vistas como precondições de práticas (linguísticas) de atores sociais. Ela assinala um conjunto de regras fundamentais que são consideradas como condições primárias de ações racionais (sentenças linguísticas). Essas estruturas profundas formam um conhecimento pré-teórico que não é explicitado pelos sujeitos sociais nas suas atividades cotidianas, mesmo que essas atividades não sejam possíveis sem a ação baseada nesse conjunto implícito de regras. Um sujeito que age (usuário da linguagem) pode ser capaz de desenvolver argumentos coerentes num discurso sem conhecer as regras que ele necessariamente segue quando realiza esses atos: ele sabe "como" realizar ações sem conhecer as 
precondições que possibilitam essas ações. As estruturas profundas devem ser descobertas para que se possam expor essas precondições relacionadas a um conhecimento do qual os sujeitos agentes não estão reflexivamente cientes. Em outras palavras, a reconstrução racional explicita um conhecimento implícito e transforma o "saber como" em um "saber que". Por causa do seu caráter implícito e pré-reflexivo, esses sistemas de regras correspondem, de acordo com Habermas, a uma forma "pura" do conhecimento, permanecendo afastados dos três interesses do conhecimento considerados em Conhecimento e interesse - e rompe as relações entre reflexão, razão e emancipação, teoria e prática, etc.

Se a reconstrução expõe o conjunto implícito de conhecimento baseado nas competências linguísticas e cognitivas, que são conhecidas e utilizadas nas atividades usuais de sujeitos agentes que não refletem sistematicamente sobre isso, então ela deve ser acessada por meio de métodos específicos, que diferem do senso comum. Porque esse conhecimento implícito dos sujeitos agentes não lhes é diretamente acessível, a sua exposição deve ser realizada por um tipo específico de investigação. O processo de reconstrução depende de um ponto de vista teórico afastado do âmbito prático das atividades ordinárias. Esse procedimento reconstrutivo torna-se possível apenas na medida em que conseguimos refletir sistematicamente sobre as regras tácitas e o conhecimento implícito a que nos referimos em nossas práticas cotidianas. Uma abordagem lógica sistemática relacionada a "ciências reconstrutivas" - é o único caminho para descrever esse sistema tácito de conhecimento. Ela deve ser descoberta através de procedimentos científicos de esclarecimento por conta de métodos de investigação. Entretanto, esses procedimentos de reconstrução não podem ser usados como um tipo de objetivação "externa" - como é feito na atitude positivista das ciências técnicas - porque eles devem adotar o ponto de vista interno do participante atuante, a fim de conseguir reconstruir sistematicamente o conjunto de regras que sujeitos atuantes empregam frequentemente nas suas atividades usuais.

Isso significa que a reconstrução deve expor não um conjunto de ilusões de um sujeito passivo, mas as competências práticas dos sujeitos atuantes envolvidos em atividades usuais que podem ser consideradas como partilhadas em comum. De acordo com Habermas, qualquer sujeito atuante "possui" necessariamente competências práticas, pois estas são condições de uma socialização normal numa sociedade humana. Em outras palavras, a "reconstrução racional" concebida por Habermas não deve revelar um conjunto de conhecimentos intuitivos válidos sob certas circunstâncias limitadas, mas um sistema de competências universalmente válidas, 
[17] Eu não teria como discutir aqui as difíceis questões concernentes ao modelo dualista concebido por Habermas das sociedades modernas (sistema/mundo da vida) nem as implicações desse modelo no dualismo metodológico, articulando uma microteoria da racionalidade relacionada a práticas comunicativas como base da integração social (perspectiva metodológica do participante) e uma macroteoria de integração sistemática em mecanismos tais como mercado e poder estatal (perspectiva metodológica do observador). Sobre essa questão, ver particularmente Outhwaite, op.cit.

[18] Habermas, Jürgen. Between facts and norms. Cambridge: The MIT Press, 1996, pp. 6-7.

[19] Para uma discussão crítica sobre essa relação, ver Alford, Fred C. “Is Jürgen Habermas' reconstructive science really science?". Theory and Society, 14, 1985, pp. 321-40; para argumentos em defesa do transcendentalismo: Kuhlmann, Wolfgang. "Philosophie und rekonstruktive Wissenschaft. Bemerkungen zu Jürgen Habermas' Theorie des kommunikativen Handelns". Zeitschrift für philosophische Forschung, 40, 2, 1986, pp. 224-34. tidas como precondição fundamental das práticas humanas - cf. o programa de pragmáticas universais. (Essa é a razão pela qual o método de reconstrução foi, sobretudo, aplicado na teoria das competências comunicativas). Por fim, se a reconstrução expõe as competências fundamentais, ela também diz respeito ao modo como essas competências foram desenvolvidas ao longo do tempo (desenvolvimento lógico).

A reconstrução rejeita a perspectiva científica exterior de objetivação "técnica" e adota o ponto de vista "interno" do participante, explicitando os sistemas implícitos de regras. Ademais, ela deve necessariamente ir além da perspectiva do sujeito atuante para poder explicitar o sistema de regras deste. A despeito de sua forte crítica ao positivismo, o método de reconstrução de Habermas não abre mão da ciência, uma vez que ele reorganiza a relação da ciência com a filosofia. A reconstrução não segue paradigmas interpretativos como a hermenêutica e a rejeição desta à explicação, pois a reconstrução tem por objetivo a articulação de métodos descritivos, interpretativos e explicativos num mesmo quadro teórico. De acordo com Habermas, a reconstrução está enraizada em um pluralismo metodológico e teórico para o qual a variedade de abordagens teóricas e metodológicas conferidas aos fenômenos sociais torna impossível restringir a sua própria perspectiva a apenas uma disciplina ${ }^{17}$. Pelo contrário, a reconstrução deve integrar e articular várias perspectivas metodológicas (participante/observador) e diferentes atitudes pragmáticas de pesquisa (hermenêutica, crítica e analítica) ${ }^{18}$. Esse pluralismo teórico e metodológico permite evitar a divisão do trabalho que levou a uma lacuna terrível entre disciplinas normativas, como a que existe entre filosofia moral e ciências empíricas.

Essa é a razão pela qual o método reconstrutivo reconfigura profundamente a relação entre ciências empíricas e filosofia na Teoria Crítica. No posfácio mencionado anteriormente de Conhecimento e interesse, Habermas foi um pouco longe, a ponto de imaginar que as ciências reconstrutivas deveriam progressivamente substituir a filosofia moral transcendental.A filosofia pode encontrar uma base sólida através das ciências reconstrutivas, de modo a referir-se a normas pré-reflexivas fundamentais que governam as práticas (da discussão racional) e a inferir regras universais da ética comunicativa a partir desses sistemas implícitos de regras. Desse modo, a filosofia moral continua sob a dependência das ciências reconstrutivas ${ }^{19}$ : ela depende do conhecimento sistemático desenvolvido por essas ciências para estar baseada nas normas de entendimento mútuo entre sujeitos atuantes em um sistema prático de regras. Referindo-se às importantes descobertas das pesquisas científicas reconstrutivas, Habermas lança sua hipótese teórica sobre a relação íntima entre práticas comunicativas e enten- 
dimento mútuo. Ao fazê-lo, a pragmática universal do entendimento comunicativo como base do seu discurso ético desenvolveu-se graças a essas ciências reconstrutivas.

Dessa forma, a filosofia precisa alcançar sua fundação nos resultados provisórios das pesquisas científicas, resultados esses que podem sempre ser confrontados e modificados por novas investigações empíricas. As hipóteses produzidas num determinado contexto são sempre falíveis e abertas a novos testes empíricos que levam à sua confirmação ou invalidação. Uma vez que Habermas não quer desenvolver uma análise transcendental baseada em meras intuições, mas sim em análises "quase transcendentais" baseadas em evidências empíricas atinentes à racionalidade prática firmada no uso corrente da linguagem, os dados empíricos obtidos pelas ciências reconstrutivas são de primeira importância. Enquanto a filosofia transcendental clássica (Kant) pretende revelar as condições de possibilidade do entendimento racional com base na pura introspecção, Habermas considera que essa racionalidade prática só pode ser descoberta pela análise empírica. Uma vez que esta sempre depende das pesquisas concretas, a "reconstrução racional" mantém um caráter hipotético. Habermas afirma que a confirmação dessas hipóteses depende da verificação indireta por parte das ciências empíricas e que a sua validade é parcialmente determinada pela maneira como elas funcionam junto a uma variedade de outras teorias através de uma cooperação produtiva. Como consequência, ele precisa considerar que sua hipótese fundamental sobre o vínculo íntimo entre comunicação linguística e entendimento mútuo - que é o centro da teoria normativa de Habermas - pode ser submetida a novas investigações empíricas que têm o "poder" de questionar tal hipótese fundamental. Enquanto nenhuma outra pesquisa contradisser essa pressuposição baseada em investigações anteriores feitas pelas ciências reconstrutivas, a Teoria Crítica pode seguir em frente referindo-se normativamente a esses sistemas práticos de regra ${ }^{20}$. Essa é a razão pela qual Habermas (nas décadas de 1970 e 1980) frequentemente descreveu seu projeto filosófico como um programa de pesquisa em aberto, em que os resultados obtidos têm um status hipotético e os vários elementos constitutivos da teoria são sucessivamente postos em questão. Em contrapartida, a síntese normativa e teórica baseada em reconstruções anteriores é o ponto de partida de novas investigações, de modo a formular novos projetos de pesquisa que investiguem essas hipóteses. Assim, essa articulação entre filosofia e ciência, concebida ao longo do programa metodológico de reconstrução é a "salvação" da investigação científica empírica que não abre mão do ponto de vista

\footnotetext{
[20] "O que eu aceito como crítica antifundacionista de todo a priori contundente e de reivindicações transcendentalistas não veta, entretanto, as tentativas de colocar as reconstruções racionais de competências supostamente básicas no banco dos réus nem de testá-las indiretamente empregando-as como contribuições nas teorias empíricas" (Habermas, J. "Interpretive social science vs. hermeneuticism". In: Haan, N. e outros (eds.).Social science as moral inquiry. Nova York:Columbia University Press, 1983, p. 261).
} 
[21] De modo mais preciso, a reconstrução surge como uma "alternativa teórica" durante um período crucial no desenvolvimento do trabalho de Habermas (que se seguiu à publicação de Conhecimento e interesse, no final da década de 1960 e início da de 1970), situado no cruzamento de três "confrontações" teóricas. Primeiramente, durante a disputa positivista nas ciências sociais e após ele (eAdorno) discutirem criticamente a ascensão do tecnocratismo na pesquisa social: a investigação social é utilizada para desenvolver estratégias aperfeiçoáveis de resolução de problemas segundo um modelo que torna o papel do cientista social semelhante ao do engenheiro, escolhendo solução técnicas aperfeiçoáveis para questões de projeto que são, na realidade, problemas práticos. Em segundo lugar, as ciências sociais interpretativas aparecem numa primeira fase como um bom substitutivo do tecnocratismo por causa da importância que elas dão ao diálogo entre investigador e "outros" e do papel central atribuído à comunicação simbolicamente estruturada (cf. o debate Habermas) Gadamer). Apesar das várias convergências com a hermenêutica, Habermas não concordou com Gadamer sobre várias questões — a sua exclusiva atenção ao "texto escrito", a ausência de considerações sobre as deformações da comunicação, bem como a ausência de crítica - e afastou-se da hermenêutica. Em terceiro lugar, Habermas afastou-se da ideia de uma autorreflexão crítica baseada no modelo de crítica ideológica, em favor de uma "crítica reconstrutiva".

[22] Ver Honneth, Axel. "Rekonstruktive Gesellchaftskritik unter genealogischem Vorbehalt. Zur Idee der 'Kritik' in der Frankfurter Schule". Deutsche Zeitschrift für Philosophie, 5, 48, 200o, pp. 729-37; Voirol, Olivier. "Axel Honneth et la sociologie. Reconnaissance et Théorie critique à l'épreuve de la recherche sociale". In: Caillé, Alain (ed.). La quête de reconnaissance. Nouveau phénomène social total. Paris: La Découverte, 2007, pp. 243-68; as diferenças entre a ideia de reconstrução normativa de Honneth e a de reconstrução racional de Habermas foi discutida por Celikates, Robin. Kritik als Praxis. Frankfurt: Campus, 2009, esp. parte 3. filosófico: reconstruções anteriores são, em princípio, integradas num quadro teórico e normativo e testadas novamente como novas "contribuições" para futuras pesquisas.

A "virada reconstrutiva" introduzida por Habermas no início da década de 1970 teve uma influência central sobre o desenvolvimento da Teoria Crítica. Desde essa "virada" metodológica, as mais importantes inovações teóricas assumiram-na como uma fundação e precondição metodológicas ${ }^{21}$. Os desenvolvimentos subsequentes da teoria normativa da comunicação de Habermas, bem como a sua última teoria do direito, baseiam-se nessa metodologia - cf. a reconstrução histórica do direito em Entre fatos e normas (1996). Isso também ocorre em vários desenvolvimentos filosóficos "pós-habermasianos", por exemplo, na teoria do reconhecimento de Honneth, que oferece hoje em dia uma atualização promissora da Teoria Crítica. O conjunto do empreendimento de Honneth é baseado na metodologia da reconstrução ${ }^{22}$, ainda que dê forte ênfase a motivos hegelianos - comparado com Habermas, cujo "interlocutor filosófico" sempre foi Kant. Seja na forma de uma "reconstrução normativa" (Honneth), seja na de uma "reconstrução racional" (Habermas), a reconstrução se tornou o método da Teoria Crítica desde a "virada reconstrutiva". Como já foi dito, a reconstrução também transformou as articulações entre filosofia e ciência, entre teoria e pesquisa, entre fundação normativa e investigação científica, quando comparadas com o modelo dialético do primeiro Horkheimer. Meu ponto é que a relação entre teoria e pesquisa na Teoria Crítica se tornou mais complicada desde a "virada reconstrutiva" - tratarei agora desse ponto.

\section{CONCLUSÃo: CONSEQUÊNCIAS E LIMITES DA RECONSTRUÇÃo}

A dialética horkeimiana da teoria e pesquisa, estabelecida no início da década de 1930, almejava a investigação sobre as condições sociais e históricas, admitindo a realização (ou não) de uma práxis emancipatória pré-teórica, especialmente no despertar para os vários obstáculos contrários a essas práticas. Graças aos métodos empíricos das ciências sociais, esse programa de pesquisa deveria investigar as razões pelas quais a hipótese filosófica dada por uma filosofia da história, que pressupõe a realização efetiva da razão, não se mostra confirmada pelas evidências empíricas. A pesquisa social serve nesse caso mais como um meio de tornar conhecidos os obstáculos de emancipação do que as disciplinas que visam fundar pressuposições normativamente filosóficas sobre práticas usuais. No começo da década de 1930, o quadro normativo da Teoria Crítica era, de certa forma, tido por certo; não valia a pena questioná-lo: ele 
se referia à extensão histórica de uma práxis ancorada num processo de forças produtivas. Em contrapartida, a pesquisa social tem uma "função" diferente no "paradigma" metodológico da reconstrução, uma vez que as ciências empíricas prestam-se, acima de tudo, à tarefa de fundação normativa em diferentes contextos, em que as normas da crítica não podem ser realmente garantidas ou distribuídas conforme o quadro total de uma filosofia "positiva" da história. As ciências reconstrutivas oferecem, sobretudo, o conhecimento metodológico necessário sobre os sistemas de regras implícitas de um entendimento mútuo, admitindo uma fundação prática e empiricamente eficiente - quase transcendental - da moral que deve estabelecer, normativamente, a Teoria Crítica. Essas regras em que estão baseadas as práticas implícitas do entendimento mútuo oferecem uma fundação normativa do modelo habermasiano de comunicação - e desempenham a mesma "função" teórica que a práxis emancipatória produtiva no modelo dialético de Horkheimer.

Em ambos os casos, um nível prático fundamental, em que estão baseadas as atividades dos sujeitos atuantes, é, simultaneamente, eficaz nas relações sociais e prejudicado pelas tendências sociais. Para Horkheimer, essa prática não pode ser completamente realizada nas condições efetivas, uma vez impedida por vários obstáculos (irracionalismo, ideologia, autoridade, etc.) e sistematicamente prejudicada na sociedade capitalista. A ideia de que essas práticas podem ser prejudicadas por certas tendências "falsas" e específicas é parte de uma análise maior das evoluções sociais e políticas de uma era. Diferentemente de Horkheimer, que sem dúvida vinculou o desenvolvimento da Teoria Crítica à pesquisa social, Habermas não foi verdadeiramente bem-sucedido na formulação de um conjunto de hipóteses teóricas que orientassem um programa sistêmico de investigações empíricas - o posfácio de Teoria da ação comunicativa é uma exceção, embora nunca tenha resultado num plano investigativo eficaz.

Se a ideia de patologias sociais do período tivesse sido formulada na forma de uma hipótese, visando assim orientar as investigações sociais empíricas, as ciências sociais teriam conseguido outro lugar na sua construção teórica, no sentido de um estudo sistemático das possibilidades sociais eficazes de práticas comunicativas. $\mathrm{O}$ que foi de algum modo negligenciado pelo método de reconstrução é a ideia de investigar sistematicamente as condiçôes sociais de realização dessas práticas emancipatórias, incluindo o estudo de vários de seus obstáculos (sociais, econômicos, institucionais, etc.). $\mathrm{O}$ uso das ciências reconstrutivas para a fundação normativa da crítica, mais do que o estudo sistemático de vários obstáculos e dificuldades sociais que impedem as práticas emancipatórias, tende a 
[23] Uma crítica semelhante foi formulada por Fred C. Afford, op. cit.

[24] Se a concepção de Habermas sobre os objetivos da investigação social não se concentra, primeiramente, nos desenvolvimentos das patologias sociais, isso ocorre para dar início a processos públicos de deliberação e verificação prática, bem como para promover as condições de comunicação democrática que permitam a adequada autorreflexão de todos aqueles que são afetados (ver Bohman, 2000): o "poder restritivo" surge das verificações práticas dos resultados da investigação, em um processo público de deliberação. privilegiar uma perspectiva "otimista". Nesse sentido, o potencial de realização efetiva dessas práticas é idealizado; e as tendências empíricas negativas que as impedem são neutralizadas. As críticas bem conhecidas e recorrentes ao "otimismo" geral da filosofia moral de Habermas, idealizando o alcance do entendimento mútuo em verdadeiras comunicações linguísticas, podem ser entendidas à luz desse privilégio metodológico.

Ao longo do modelo dialético de teoria e pesquisa, os processos exploratórios de investigação desempenharam um papel importante na formação da síntese teórica. A investigação social teve consequências importantes sobre os tipos de diagnósticos formulados na síntese teórica da Teoria Crítica. Na condição de "apresentação" provisória, a teoria deve ser constantemente redefinida pelos processos de investigação. Em contrapartida, a reconstrução supõe uma relação entre teoria e pesquisa que se desenvolve em favor da primeira: a construção teórica está à procura de um conjunto de descrições empíricas fornecidas pelas ciências reconstrutivas de modo a formular uma síntese filosófica normativa e descritiva.A abordagem filosófica busca descrições fornecidas pelas ciências empíricas que são, sobretudo, adequadas ao seu projeto ${ }^{23}$ - o que é reforçado pela divisão de trabalho entre teoria normativa e pesquisa empírica (contrariamente ao programa interdisciplinar proposto por Horkheimer, as pessoas que realizam a pesquisa não são as mesmas que estão produzindo a síntese teórica). Ainda que a ciência empírica desempenhe um papel importante na concepção de Habermas sobre a Teoria Crítica, por causa da fundação normativa da filosofia moral nas práticas efetivas, a pesquisa social não tem o mesmo "poder restritivo" que o modelo dialético de teoria e pesquisa ${ }^{24}$. Como consequência, em vez de uma "verdadeira" dialética da teoria e pesquisa, a reconstrução introduz outro tipo de relação entre ambas, em que o "poder" de investigar é mais ou menos dissolvido em favor da construção filosófica.

Embora as grandes dificuldades de juntar numa única estrutura teórica as questões normativas tratadas pela filosofia moral e social, de um lado, e as pesquisas sociais realizadas pelas ciências empíricas, de outro, não resultem somente das simples questões teóricas discutidas acima - em razão das restrições institucionais e acadêmicas que atualmente organizam as pesquisas sociais - certas concepções específicas podem contribuir mais do que outras para esse fenômeno. Uma dessas dificuldades reside na situação teórica da filosofia normativa, de um lado, e na das ciências sociais, de outro. Desde a "mudança de paradigma" na filosofia política (encorajada por John Rawls no seu Teoria da justiça), que passou a lidar com meras questões normativas sem referência a práticas efetivas descritas pelas ciências sociais (mudança essa que também in- 
fluenciou o desenvolvimento da Teoria Crítica), ficou cada vez mais difícil conceber e defender uma dialética da teoria e pesquisa. Além disso, a ultraespecialização das ciências sociais empíricas e a sua completa rejeição de temas normativos, bem como das abordagens filosóficas, dificultam ainda mais essa cooperação ${ }^{25}$. Tendo em mente as várias dimensões dessa situação, eu gostaria de delinear outras possíveis direções da Teoria Crítica, a fim de conceber uma dialética da teoria e pesquisa. Como vimos, a reconstrução levanta alguns problemas sobre a articulação entre pesquisa e teoria, mas eu imagino que seria possível modificar o modelo de reconstrução, possibilitando uma reconexão com alguns elementos importantes do modelo dialético segundo o "paradigma da reconstrução" 26 .

Em primeiro lugar, parece-me que as ciências empíricas e a pesquisa social não deveriam servir apenas como base para a fundação normativa da Teoria Crítica, buscando não só explicitar - de modo sistemático - práticas emancipatórias em nossas atividades atuais, mas também investigar sistematicamente as condições sociais, econômicas, institucionais e políticas de realização eficazes dessas práticas. Como vimos, se a Teoria Crítica considera que as práticas em que a sua fundação normativa está baseada são eficazes na realidade social, ela também considera que as mesmas práticas são sistematicamente prejudicadas sob condições patológicas que precisariam ser criticamente representadas. Como resultado dessa perspectiva, um dos objetivos da pesquisa social deveria ser investigar mais sistematicamente o modo como as deformações dessas práticas estão emergindo, aumentando e se reproduzindo, e quais as configurações institucionais específicas que as reforçam. Para evitar o problema discutido anteriormente sobre a "idealização" da reconstrução, essa perspectiva deveria evitar o "exagero moral" que tende a negligenciar aquilo que "resiste" ou "impede" a realização ou o desenvolvimento dessas práticas.

Em segundo lugar, essa proposta está próxima do programa de pesquisa sobre patologias sociais do presente que Habermas propôs como conclusão de Teoria da ação comunicativa (1981). O ponto, porém, é conseguir reunir, numa íntima relação, o método reconstrutivo e o diagnóstico do presente. Desenvolver tal diagnóstico significa investigar as tendências atuais nos termos da possível realização de potenciais emancipatórios baseados em práticas eficazes. Os arranjos sociais, econômicos e políticos devem ser considerados pela pesquisa social sob a perspectiva de suas possibilidades para incentivar ou prejudicar tais práticas emancipatórias. Significa, portanto, fazer uma "cartografia" política, social e econômica do presente e das diferentes "forças" sociais permitindo - ou não - tais potenciais emancipatórios. Se o método de reconstrução estivesse mais envolvido com esses
[25] O modelo metodológico de Habermas pode ser considerado central para a Teoria Crítica atual, mas podemos ser menos "entusiastas" do que muitos autores que o consideram uma "superação" definitiva do modelo dialético de Horkheimer (ver, por exemplo, Baynes, Kenneth. "Rational reconstruction and social criticism: Habermas's model of interpretive social science in hermeneutics in ethics and social theory". Philosophical forum, 21, 1-2, 1989, pp. 122-45; Dryzek, John S. "Critical theory as a research program". In: White, S. K. (ed.). The Cambridge companion to Habermas. Nova York: Cambridge University Press, 1995 , pp. 97-123; Bohman, James. "Participants, observers and critics: practical knowledge, social perspectives, and critical pluralism". In: Rehg, William e Bohman, James (ed.).Pluralism and the pragmatic turn. The transformation of Critical Theory. Cambridge: The MIT Press, 2001, pp. 87-114).

[26] Algumas interpretação recentes do programa inicial de Horkheimer estão abrindo novas perspectivas, ver: Kavoulakos, Konstantinos, “From Habermas to Horkheimer's Early Work: Directions for a Materialist Reconstruction of Communicative Critical Theory", in Telos, 2005, p.39-62; Berendzen, J.C., "Suffering and theory: Max Horkheimer's early essays and contemporary moral philosophy", in Philosophy $\&$ Social Criticism, 36, 9, 2010, pp.1019-1037; Abromeit, John, Max Horkheimer and the Foundations of the Frankfurt School, Cambridge University Press, 2011. 
Recebido para publicação em 19 de outubro de 2011.

\section{NOVOS ESTUDOS}

CEBRAP

93, julho 2012

pp. 81-99 diagnósticos históricos e políticos, ele seria capaz de resgatar alguns elementos importantes do modelo dialético.

Por fim, essas propostas só podem ser cumpridas se a relação entre teoria e pesquisa se realiza de uma maneira dialética. A pesquisa deve sempre ter um "poder restritivo" de redefinir construções teóricas e oferecer possibilidades para novos diagnósticos. Em outras palavras, o processo de investigação específico da ciência social deve ter um forte "poder negativo" sobre a teoria para também reforçar as possibilidades práticas da sua realização na história.

Olivier VoIrol é professor da Universidade de Lausanne e pesquisador do Instituto de Pesquisa Social de Frankfurt. 